\title{
KAJIAN KELAYAKAN EKONOMI PADA RUAS JALAN CIANJUR - SUKANAGARA KABUPATEN CIANJUR KM.BDG 68+440 s/d KM.BDG $174+180$
}

\author{
Oleh : \\ Yudi Sekaryadi \\ Chelsa Nurhasnasary, \\ Fakultas Teknik Program Studi Teknik Sipil, \\ Universitas Suryakancana
}

\begin{abstract}
ABSTRAK
Jalan merupakan salah satu prasarana transportasi yang sering digunakan, jalan mempunyai peranan penting dalam kehidupan khususnya untuk kelancaran transportasi. Tentunya diharapkan jalan yang aman, nyaman dan lancar menjadi kebutuhan yang harus terpenuhi demi mencapai cita-cita bersama. Salah satu yang menimbulkan dampak negatif diruas jalan dikota Cianjur tersebut adalah diruas jalan Cianjur - Sukanagara yang ditinjau dari segi ekonomi berupa kehilangan waktu karena waktu perjalanan yang lama serta bertambahnya biaya operasi kendaraan. Selain itu, timbul pula dampak negatif terhadap lingkungan yang berupa peningkatan polusi udara karena gas racun CO serta peningkatan gangguan suara kendaraan (kebisingan).

Jaringan jalan diruas Cianjur - Sukanagara tersebut harus mampu meningkatkan aksesibilitas dan mobilitas penduduk antar simpul wilayah yang lebih luas dari pada jaringan jalan kabupaten. Tujuan penataan dan pengembangan di bidang transportasi jalan raya adalah untuk penyediaan prasarana jalan raya yang handal untuk mengimbangi pertumbuhan jenis dan jumlah kendaraan yang sedemikian pesat sehingga tercipta sistem transportasi yang efisien dan efektif.
\end{abstract}

Ruas jalan Cianjur - Sukanagara sudah mencapai tingkat maksimal dalam pemanfaatan nya secara ekonomi dengan adanya produksi pertanian dan perkebunan. Pemanfaatan jalan yang didapat dari analisis kelayakan ekonomi pembangunan jalan dengan menghitung menggunakan beberapa parameter yaitu NPV (Net Present Value), BCR (Benefit Cost Ratio) dan IRR Intertal Rate of Return.

Perbandingan antara biaya yang dibutuhkan dengan manfaat ekonomi yang diperoleh yaitu dengan jumlah biaya jalan sebesar $\mathrm{Rp}$ 67.788.484.260,00 dan pendaptan ekonomi tersebut sebesar Rp 13.189.000,00.

Kata kunci : ekonomi, biaya, jalan, transportasi.

\section{PENDAHULUAN}

Jalan merupakan salah satu prasarana transportasi yang sering digunakan, jalan mempunyai peranan penting dalam kehidupan khususnya untuk kelancaran transportasi. Tentunya diharapkan jalan yang aman, nyaman dan lancar menjadi kebutuhan yang harus terpenuhi demi mencapai cita-cita bersama.
Cianjur merupakan kota yang kaya dengan hasil bumi seperti rempah-rempah nya jadi infrastrukur seperti jalan sangat penting kehadiranya. Masalah transportasi saat ini sudah merupakan masalah utama yang sulit dipecahkan di kota-kota besar. Kemacetan lalu lintas yang terjadi sudah sangat mengganggu aktivitas penduduk. Telah kita ketahui, bahwa kemacetan akan menimbulkan berbagai dampak negatif, baik terhadap pengemudi 
maupun ditinjau dari segi ekonomi dan lingkungan.

Salah satu yang menimbulkan dampak negative diruas jalan dikota Cianjur tersebut adalah diruas jalan Cianjur Sukanagara yang ditinjau dari segi ekonomi berupa kehilangan waktu karena waktu perjalanan yang lama serta bertambahnya biaya operasi kendaraan. Selain itu, timbul pula dampak negatif terhadap lingkungan yang berupa peningkatan polusi udara karena gas racun $\mathrm{CO}$ serta peningkatan gangguan suara kendaraan (kebisingan). Jaringan jalan nasional dan provinsi sebagaimana diamanatkan dalam Undang-Undang Republik Indonesia Nomor 38 Tahun 2004 tentang Jalan, memiliki peranan yang sangat penting terhadap peningkatan perekonomian wilayah.

\section{TINJAUAN PUSTAKA}

\section{PENGERTIAN JALAN}

Jalan adalah prasarana transportasi darat yang meliputi segala bagian jalan, termasuk bangunan pelengkap, dan perlengkapannya yang diperuntukkan bagi lalulintas, yang berada dipermukaan tanah, diatas permukaan tanah, dibawah permukaan tanah, serta diatas permukaan air, kecuali jalan kereta api dan jalan kabel (UU No. 38 tahun 2004 tentang Jalan). Bagian-bagian jalan meliputi ruang manfaat jalan, ruang milik jalan, dan ruang pengawasan jalan :

a. Ruang manfaat jalan meliputi badan jalan, saluran tepi jalan, dan ambang pengamannya.

b. Ruang milik jalan meliputi ruang manfaat jalan dan sejalur tanah tertentu diluar ruang manfaat jalan.

c. Ruang pengawasan jalan merupakan ruang tertentu diluar ruang milik jalan yang ada dibawah pengawasan penyelenggara jalan.

\section{BIAYA PEMBANGUNAN JALAN}

Pada pelaksanaan pembagunan jalan, mulai dari ide, studi kelayakan, perencanaan, pelaksanaan sampai pada operasi dan pemeliharaan membutuhkan berbagai macam biaya. Dalam analisis kelayakan ekonomi biaya-biaya tersebut dikelompokan menjadi beberapa kelompok sehingga memudahkan dalam analisis perhitungannya. Menurut Kuiper (1971) semua biaya itu dikelompokan menjadi Biaya Modal (Capital cost) dan Biaya Tahunan (Annual Cost).

- Biaya Modal ( capital cost ) : Biaya modal menurut ( Kuiper 1971 ) adalah jumlah semua pengeluaran yang dibutuhkan mulai dari pra studi sampai proyek selesai dibangun. Semua pengeluaran yang termasuk biaya modal ini dibagi menjadi dua bagian yaitu :

1. Biaya langsung ( direct cost) dan

2. biaya tidak langsung (indirect cost).

Biaya Tahunan (Annual Cost) : Ketika proyek selasai dibanagun merupakan waktu awal dari umur proyek sesuai dengan rekayasa teknik yang telah dibuat pada waktu detail desain. Pada saat ini pemanfaatan proyek mulai dilaksanakan, dimana selama pemanfaatan proyek ini masih memerlukan biaya sampai umur proyek selesai. Biaya ini merupakan beban yang harus dipikul oleh pihat pemilik/owner. Padaprinsipnya biaya yang masih diperlukan sepanjang umur proyek ini, merupakan biaya tahunan yang terdiri dari 3 komponen, yaitu :

1. Bunga

2. Depresiasi atau Amortisasi

3. Biaya Operasi dan Pemeliharaan.

\section{MANFAAT PEMBANGUNAN JALAN}

Manfaat pembangunan jalan pada prinsipnya dapat dibagi menjadi manfaat langsung dan manfaat tidak langsung. Manfaat langsung adalah manfaat yang dirasakan langsung oleh pengguna jalan dalam bentuk consumer surplus, sedangkan manfaat tidak langsung adalah manfaat yang dirasakan oleh produsen dalam hal ini petani berupa producer surplus.

- Manfaat oleh konsumen (Consumer Surplus) : Konsep pendekatan Consumer Surplus adalah dengan adanya pengurangan harga yang dikeluarkan oleh konsumen untuk memperoleh atau menggunakan 
produk tertentu, selisih harga awal dengan harga baru yang harus dikelurkan merupakan penghematan (saving) bagi konsumen, sementara itu sesuai dengan fungsi (kurva) demand-nya maka akan terdapat penambahan volume, sehingga manfaat total adalah perkaitan jumlah volume baru dengan selisih harga yang terjadi.

- Manfaat oleh Produser (Producer Surplus) : Analisa producer surplus merupakan salah satu sebagai salah satu penilaian dalam mengevaluasi kelayakan proyek. Menurut road note 5 (2004), pendekatan analisis producer surplus mengacu pada keadaan dimana volume lalu lintas rendah yang mengakibatkan kurangnya justifikasi surplus konsumen, dan semata-mata untuk meningkatkan aksesibilitas pada suatu wilayah yang direncanakan akan dikembangkan.

Dalam hal ini kriteria keuntungan (benefit) yang digunakan iaah semua surplus yang dinikmati oleh produsen barang dan jasa yang dijual dan tercangkup dalam daerah pengaruh proyekkeuntungan akibat perubahan volume dan biaya transport sangat tergantung pada besarnya keuntungan akibat perubahan harga produk (pertanian) dilokasi produksi.

Dalam kajian jalan Cianjur - Sukanagara, pendekatan surplus produsen dilakukan dengan memperhatikan sector pertanian oleh karena jalan tersebut melewati daerah pertanian. Beberapa asumsi yang akan digunakan adalah :

1. Dengan adanya proyek jalan Cianjur Sukanagara, mengakibatkan peningkatan kepada luas areal tanam atau peningkatan tingkat produk.

2. Biaya transportasi berkurang karena aksesbilitasinya yang lebih baik dari investasi lainnya.

3. Produk yang dijual dengan harga seragam dilokasi yang berjarak tertentu.
4. Peningkatan produk pertanian tidak akan meningkatkan jatuhnya harga pasar, sehingga harga jual tetap dan petani dapat menjual hasil tani sebanyak mungkin.

5. Komsumsi rumah tangga tetap dan tidak dipengaruhi oleh produksi.

6. Biaya transportasi dan produksi sama untuk semua petani.

\section{STUDI KELAYAKAN EKONOMI}

Studi kalayakan menurut kelompok keahlian (KK) transportasi ITB adalah suatu kegiatan penelitian atau studi yang dilakukan secara komprehensif dari berbagai aspek dalam usaha tingkat kelayakan proyek. Sedangkan menurut Imab Suharto studi kelayakan adalah kegiatan awal berupa studi terhadap berbagai alternative sebelum diambil keputusan untuk melakukan investasi. Adapun yang dimaksud dengan investasi adalah penggunaan sumber daya (resources) dengan tujuan untuk memperoleh manfaat (keuntungan) sebesar - besarnya dimasa yang akan datang (Suad Husnan, 1994). Sumber daya yang digunakan tersebut meliputi dana (money), manusia (man), peralatan (machine), material, metode (method) dan lain - lain.

\section{- Tujuan studi kelayakan :}

1. Untuk mengetahui tingkat keuntungan yang dapat dicapai melalui investasi dan menghindari pemborosan sumber daya akibat investasi yang tidak menguntungkan.

2. Mengadakan penilaian terhadap peluang investasi yang ada sehingga kita dapat memilih alternatif yang paling menguntungkan dan menentukan prioritas investasi.

\section{- Aspek studi kelayakan :}

Mengingat bahwa tujuan dari studi kelayakan adalah mengkaji tingkat kelayakan dari suatu proyek, dimana kelayakan dimaksud adalah dari berbagai aspek, maka lingkup studi kelayakan meliput semua aspek yang ditinjau ataupun dikaji kelayakannya. Secara umum aspek-aspek yang ditinjau dalam studi kelayakan terdiri dari : 
a. Aspek kebutuhan (demand)

b. Aspek teknis

c. Aspek finansial

d. Aspek ekonomi / social

e. Aspek lingkungan

f. Aspek kebijakan politik

g. Aspek kelembagaan /manajerial.

\section{- Analisa Kelayakan Ekonomi}

Studi kelayakan ekonomi berbeda dengan kelayakan finansial, suatu perhitungan dikatakan perhitungan finansian bila yang berkepentingan langsung dalam manfaat dan biaya proyek adalah individu adalah pengusaha. Dalam hal ini, yang dihitung sebagai manfaat adalah apa yang diperoleh 0rang-orang atau badan-badan swasta yang menanamkan modalnya atau yang melakukan investasi. Sebaliknya, suatu perhitungan dikatakan perhitungan ekonomi, bila yang berkepentingan langsung dalam manfaat dan biaya investasi adalah pemerintah dan masyarakat secara keseluruhan.

\section{- Parameter Kelayakan Ekonomi}

Sebagaimana dalam tabel diatas, kriteria kelayakan ekonomi pembangunan jalan dilakukan dengan menghitung beberapa parameter yaitu :

\section{a. Benefit Cost Ratio (BCR) :}

Adalah perbandingan antara Present Valur Benefit dibagi dengan Present Valur Cost. BCR dengan nilai lebih besar 1 menunjukan bahwa program pembangunan jalan akan menguntungkan, sedangkan BCR kurang dari 1 menujukan bahwa proyek tersebut tidak layak. Nilai ini dilakukan berdasarkan nilai sekarang, yaitu dengan membandingkan selisih manfaat dengan biaya yang lebih besar dari nol dan selisih manfaat dengan biaya lebih kecil dari nol. Persamaan umum dalam mengitung BCR adalah sebagai berikut :

$$
\begin{aligned}
& \text { B/Cnett } \\
& \text { Present Value Nett Benefit }
\end{aligned}
$$

b. Net Present Value (NPV) :
Adalah selisih antara present Value Benefit dikurangi dengan Present Value Cost. Suatu proyek dapat diterima apabila memiliki nilai akhir yang lebih besar dari nol, Net Present Value (NPV) pada akhirnya umur rencana harus lebih besar dari pada nol. Hal tersebut menggunakan tingkat bunga untuk memperkirakan selisih antara biaya dan manfaat pada saat ini dan masa yang akan datang.

$$
\begin{aligned}
& \text { NPV }=(\text { PVbenefit }- \text { Pvcost })=\text { Positif } \\
& \text { c. Internal Rate of Return }(\text { IRR }) \text { : }
\end{aligned}
$$

Adalah besarnya tingkat suku bunga pada saat nilai $\mathrm{NPV}=0$. Nilai IRR dari suatu proyek harus lebih besar dari nilai suku bunga yang berlaku atau yang ditetapkan dipakai dalam perhitungan kelyakan proyek. Nilai ini digunakan untuk memperoleh suatu tingat bunga pada kondisi NPV $=0$. Perhitungan untuk memperoleh IRR ini dilakukan dengan coba-coba. Persamaan umum untuk metode ini adalah sebagai berikut:

$$
\mathbf{N P V}=\sum_{i=0}^{n}\left[(\mathbf{B i}-\mathbf{C i})+\left(\mathbf{I R R}^{-\mathbf{1}}\right)\right]
$$

Pada dasarnya perhitungan kelayakan ekonomi pembangunan jalan mnegacu pada perbandingan antara kondisi tanpa dan dengan proyek, sehingga diketahui keuntungan yang timbul karena adanya pembangunan jalan.

\section{METODOLOGI PENELITIAN}

\section{Penentuan Lokasi}

Ruas jalan Cianjur - Sukanagara yang merupakan penentuan penulis untuk memetukan bahwa pada jalan Cianjur Sukanegara terdapat manfaat pembangunan jalan pada kelayakan ekonomi yang tinggi. Bardasarkan dari Bima Marga propinsi jawa barat terdapat dalam 3 ruas jalan, sebagaimana pada tabel di bawah ini : 
Tabel 3.1 Ruas Jalan Cianjur - Sukanegara

\begin{tabular}{|c|l|c|c|c|}
\hline No & \multicolumn{1}{|c|}{ Nama Ruas Jalan } & $\begin{array}{c}\text { Panjang } \\
(\mathrm{m})\end{array}$ & $\begin{array}{c}\text { Lebar } \\
(\mathrm{m})\end{array}$ & $\begin{array}{c}\text { Kondisi dan } \\
\text { Jenis Permulaan }\end{array}$ \\
\hline 1 & $\begin{array}{l}\text { SP3 Printis Kemerdekaan } \\
\text { (Ps hym-cibeber) }\end{array}$ & 10,74 & 5 & Hotmix Baik \\
\hline 2 & Jalan Raya Cibeber & 3,51 & 4 & Hotmix Sedang \\
\hline 3 & Cibeber - Sukanegara & 25,97 & 4 & Hotmix Rusak \\
\hline 4 & $\begin{array}{l}\text { Jalan Raya Sukanegara } \\
\text { ( Sukanegara ) }\end{array}$ & 2,24 & 5 & Hotmix Rusak \\
\hline
\end{tabular}

Sumber : Binamarga propinsi jawa barat

\section{- Flow chart Analisis Kelayakan}

\section{Ekonomi}

Pada tahapan analisis kelayakan ekonomi ini penulis diperlihatkan dalam skema flow chart sebagai berikut :

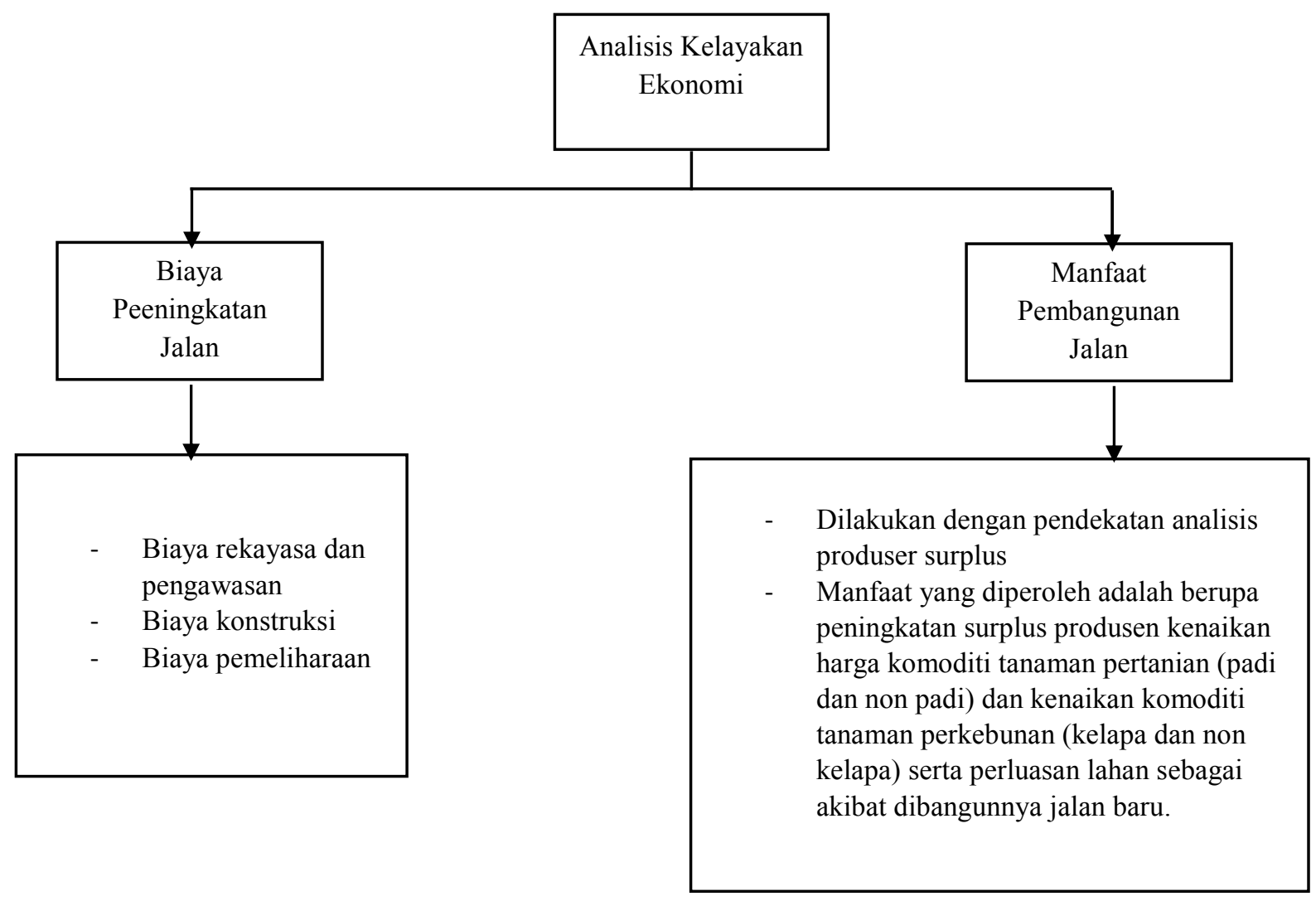




\section{- Biaya peningkatan jalan}

Biaya peningkatan yang di kaji adalah sesuai dengan kebutuhan agar kondisi jalan menjadi lebih baik, diantaranya :

Tabel 3.2 Biaya Pembangunan Jalan

\begin{tabular}{|r|l|c|c|l|r|r|}
\hline No & \multicolumn{1}{|c|}{ Nama Ruas } & Panjang (km) & Lebar $(\mathbf{m})$ & Jenis konstruksi & Harga satuan/km & \multirow{2}{*}{ Jumlah biaya } \\
\hline 1 & Psr hym - Cibeber & 10.74 & 5 & Aspal hotmix & $3,703,797,000$ & $39,778,779,780.00$ \\
\hline 2 & Jln Raya Cibeber & 3.51 & 4 & Aspal hotmix & $3,231,672,000$ & $11,343,168,720.00$ \\
\hline 3 & Cibeber - Sukanagara & 2.59 & 4 & Aspal hotmix & $3,231,672,000$ & $8,370,030,480.00$ \\
\hline 4 & Jalan Raya Sukanagara & 2.24 & 5 & Aspal hotmix & $3,703,797,000$ & $\mathbf{8 , 2 9 6 , 5 0 5 , 2 8 0 . 0 0}$ \\
\hline \multicolumn{7}{|c|}{ Jumlah } \\
\hline
\end{tabular}

Sumber : Pemerintah Provinsi Jawa Barat

\section{- Manfaat pembangunnan jalan}

Konsep pendekatan Consumer Surplus adalah dengan adanya pengurangan harga yang dikeluarkan oleh konsumen untuk memperoleh atau menggunakan produk tertentu, selisih harga awal dengan harga baru yang harus dikelurkan merupakan penghematan (saving) bagi konsumen, sementara itu sesuai dengan fungsi (kurva) demand-nya maka akan terdapat penambahan volume, sehingga manfaat total adalah perkaitan jumlah volume baru dengan selisih harga yang terjadi.

Grafik konsep pendekatan surplus pada gambar dibawah ini :

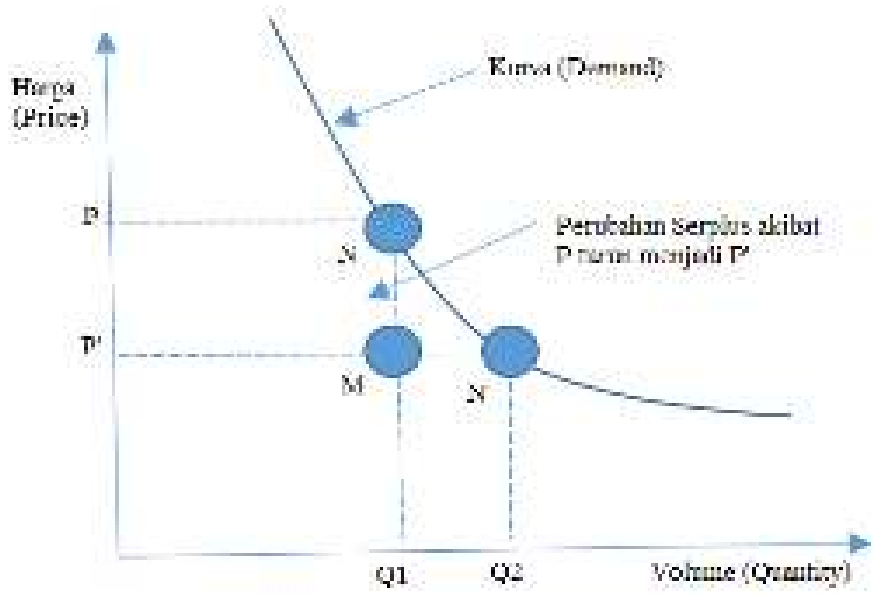

Perubahan Surplus Konsumen

Sumber : Heggie, I.G, "Transport Engineering Economic”(1992) 
Dari gambar di atas menunjukan bahwa besarnya perubahan surplus total digambarkan oleh bidang yang berada di bawah kurva D dan terletak antara garis harga $\mathrm{P}$ dengan $\mathrm{p}$ '. besarnya perubahan surplus total ini dapat diuraikan menjadi dua kelompok, yaitu:

1. Komponen yang dirasakan oleh pengguna/konsumen lama (q). perubahan surplus ini merupakan penghematan (saving) yang dinikmati oleh $\mathrm{q}$ akibat turunnya harga dari $\mathrm{P}$ menjadi P'. Besarnya penghematan ini adalah :

$$
=\mathbf{q}\left(\mathbf{P}-\mathbf{P}^{\prime}\right)
$$

2. Komponen yang dirasakan oleh pengguna baru. Jumlah pengguna baru tersebut adalah :

$$
=\left(\mathbf{q}-\mathbf{q}^{\prime}\right)
$$

Besarnya keuntang yang dinikmati oleh pengguna baru didekati dengan luas segitiga MNN'. Sehingga besarnya keuntungan oleh pengguna jalan akibat turunnya harga menjadi :

Dimana :

$$
=0,5\left(P-P^{\prime}\right)\left(\mathbf{q}-\mathbf{q}^{\prime}\right)
$$

$\mathrm{P} \quad=$ Biaya Operasi Kendaraan tanpa proyek.

$\mathrm{P}^{\prime} \quad=$ Biaya Operasi kendaraan dengan adanya proyek jalan.

$\mathrm{q}=$ Volume kendaraan normal.

q' = volume kendaraan normal ditambah dengan bangkitan.

\section{PENGOLAHAN DAN ANALISIS DATA Biaya Peningkatan Jalan}

Data yang mengenai perbaikan jalan Cianjur Sukanagara menurut Dinas Bina Marga Kabupaten Cianjur - Sukanagara dijelaskan pada tabel berikut :

Tabel 4.1 Ruas Jalan Cianjur - Sukanagara

\begin{tabular}{|c|c|c|c|c|}
\hline No & Nama Ruas Jalan & Panjang & Lebar & Kondisi dan \\
& & $(\mathrm{m})$ & $(\mathrm{m})$ & Jenis Permulaan \\
\hline 1 & SP3 Printis Kemerdekaan & 10,74 & 5 & Hotmix Baik \\
\hline 2 & (Ps hym-cibeber) & 3,51 & 4 & Hotmix Sedang \\
\hline 3 & Jalan Raya Cibeber & 2.59 & 4 & Hotmix Rusak \\
\hline 4 & Cibeber - Sukanegara & 2,24 & 5 & Hotmix Rusak \\
& Jalan Raya Sukanegara & & & \\
\hline
\end{tabular}

Sumber : Dinas Bina Marga Kabupaten Cianjur

Sedangkan data perbaikan jalan Cianjur Sukanagara adalah sebagai berikut pada tabel di bawah ini :

Tabel 4.2 Ruas Jalan dengan Panjang, Lebar dan Jenis Penanganannya

\begin{tabular}{|l|l|c|c|c|}
\hline No & Nama Ruas & $\begin{array}{c}\text { Panjang } \\
(\mathbf{m})\end{array}$ & $\begin{array}{c}\text { Lebar } \\
(\mathbf{m})\end{array}$ & Jenis Penanganan \\
\hline
\end{tabular}




\begin{tabular}{|c|c|c|c|c|}
\hline 1 & Psr hym - Cibeber & 10,74 & 5 & Overlay/hotmix \\
\hline 2 & Psr hym - Cibeber & 10,74 & 1 & $\begin{array}{c}\text { Overlay, pelebaran } \\
\text { dgn beton }\end{array}$ \\
\hline 3 & Jln Raya Cibeber & 3,51 & 4 & $\begin{array}{c}\text { Overlay dgn } \\
\text { hotmix }\end{array}$ \\
\hline 4 & Cibeber - Sukanagara & 2.59 & 4 & $\begin{array}{c}\text { Overlay dgn } \\
\text { hotmix }\end{array}$ \\
\hline 5 & Cibeber - Sukanagara & 2.59 & 1 & $\begin{array}{c}\text { Pelebaran dengan } \\
\text { beton }\end{array}$ \\
\hline 6 & Jalan Raya Sukanagara & 2,24 & 5 & Overlay \\
\hline
\end{tabular}

Sumber : Dinas Provinsi Jawa Barat

Hasil perhitungan sesuai biaya peningkatan jalan Cianjur - Sukanagara disesuaikan

dengan kebutuhan lapangan, yaitu sebagai berikut :

Tabel 4.3 Perkiraan biaya penambahan lapisan overlay

\begin{tabular}{|c|c|c|c|c|c|c|}
\hline No & Nama Ruas & Panjang (km) & Lebar (m) & Jenis konstruksi & Harga satuan $/ \mathbf{k m}$ & Jumlah biaya \\
\hline 1 & Psr hym - Cibeber & 10.74 & 5 & Aspal hotmix & $3,703,797,000$ & $39,778,779,780.00$ \\
\hline 2 & JIn Raya Cibeber & 3.51 & 4 & Aspal hotmix & $3,231,672,000$ & $11,343,168,720.00$ \\
\hline 3 & Cibeber - Sukanagara & 2.59 & 4 & Aspal hotmix & $3,231,672,000$ & $8,370,030,480.00$ \\
\hline 4 & Jalan Raya Sukanagara & 2.24 & 5 & Aspal hotmix & $3,703,797,000$ & $8,296,505,280.00$ \\
\hline \multicolumn{6}{|c|}{ Jumlah } & $67,788,484,260.00$ \\
\hline
\end{tabular}

Sumber : Pemerintah Provinsi Jawabarat

\section{Analisis Kelayakan Ekonomi}

Kelayakan ekonomi, dalam analisis ini lebih didasarkan kepada manfaat yang akan diperoleh masyarakat jika pembangunan fisik (proyek) dilaksanakan. Nilai ekonomi suatu proyek dihitung dari manfaat langsung bagi kepentingan umum, biasanya berwujud penghematan atau efisiensi yang dinominalkan dalam mata uang berlaku yang bisa diberikan karena realisasi dari proyek tersebut.

Kelayakan finansial, tujuan analisis ini berdasarkan pada kepentingan ekonomi pemilik proyek dalam artian seberapa besar manfaat berupa keuntungan yang diperhitungkan dalam mata uang yang berlaku yang diperoleh pemilik modal atau pekerjaan karena terlaksananya proyek tersebut. Kelayakan finansial ini terdiri dari analisis keuntungan dan biaya (benefit-cost ratio), nilai sekarang (net present value), dan laju pengembalian modal (internal rate of return). Dalam prakteknya ketiga macam analisis kelayakan finansial ini juga disebut analisis ekonomi teknik, sehingga sering mengaburkan maksud dari analisis kelayakan ekonomi.

\section{Peningkatan Jalan Surplus Produsen}

\section{Pendapatan Produsen}

Tabel 4.27 Rekapitulasi pendapatan produsen

\begin{tabular}{|c|c|c|}
\hline No & Kecamatan & Jumlah Pendapatan Produsen \\
\hline 1 & Cibeber & $\mathbf{8 5 8 2 5 0 0 . 0 0}$ \\
\hline
\end{tabular}




\begin{tabular}{|c|c|c|}
\hline 2 & Campaka & $\mathbf{8 3 4 2 5 0 0 . 0 0}$ \\
\hline 3 & CampakaMulya & $\mathbf{8 2 2 2 5 0 0 . 0 0}$ \\
\hline 4 & Sukanagara & $\mathbf{8 6 2 2 5 0 0 . 0 0}$ \\
\hline 5 & Pagelaran & $\mathbf{8 0 6 2 5 0 0 . 0 0}$ \\
\hline 6 & Kadupandak & $\mathbf{7 9 0 2 5 0 0 . 0 0}$ \\
\hline & Jumlah & $\mathbf{4 9 7 3 5 0 0 0 . 0 0}$ \\
\hline
\end{tabular}

Surplus produsen di atas diperoleh dari jumlah setiap pendapatan produsen per kecamatan dan direkapitulasi dari jumlah setiap Kecamatan yang diteliti oleh penulis.

Tabel 4.29 Rekapituslasi pendapatan produsen setelah perbaikan jalan

\begin{tabular}{|c|c|c|}
\hline No & Kecamatan & Jumlah Pendapatan Produsen \\
\hline 1 & Cibeber & 10710000.00 \\
\hline 2 & Campaka & 10470000.00 \\
\hline 3 & CampakaMulya & 10374000.00 \\
\hline 4 & Sukanagara & 10790000.00 \\
\hline 5 & Pagelaran & $\mathbf{1 0 3 1 0 0 0 0 . 0 0}$ \\
\hline 6 & Kadupandak & $\mathbf{1 0 2 7 0 0 0 0 . 0 0}$ \\
\hline & Jumlah & $\mathbf{6 2 9 2 4 0 0 0 . 0 0}$ \\
\hline
\end{tabular}

Dari tabel diatas dapat disimpulkan bahwa surplus produsen pada jalan Cianjur -
Sukanagara yang sebelum diperbaiki pada tahun 2014 adalah sebagai berikut :

\begin{tabular}{|l|l|r|}
\hline No & \multicolumn{1}{|c|}{ Uraian } & \multicolumn{1}{c|}{$\begin{array}{c}\text { Nilai } \\
\text { (Rp) }\end{array}$} \\
\hline $\mathbf{1}$ & Biaya Produksi Petani pada Tahun 2014 & $18,154,055,767.50$ \\
\hline $\mathbf{2}$ & Biaya Transportasi & $676,963,650.00$ \\
\hline $\mathbf{3}$ & Harga Jual Petani & $15,501,504,315.00$ \\
\hline $\mathbf{4}$ & Surplus Produser & $49,735,000.00$ \\
\hline
\end{tabular}

Sedangkan Surplus Produsen setelah perbaikan jalan pada tahun 2015 adalah sebagai berikut :

\begin{tabular}{|c|c|c|}
\hline No & Uraian & $\begin{array}{l}\text { Nilai } \\
\text { (Rp) }\end{array}$ \\
\hline $\mathbf{1}$ & Biaya Produksi Petani pada tahun 2015 & $10,982,494,507.50$ \\
\hline
\end{tabular}




\begin{tabular}{|r|l|r|}
\hline $\mathbf{2}$ & Penurunan Biaya Transportasi & $400,431,097.00$ \\
\hline $\mathbf{3}$ & Harga Jual Petani & $12,008,809,000.00$ \\
\hline $\mathbf{4}$ & Surplus Produsen & $62,924,000.00$ \\
\hline $\mathbf{5}$ & Peningkatan Surplus & $13,189,000.00$ \\
\hline
\end{tabular}

Sehingga manfaat perbaikan jalan Cianjur - Sukanagara adalah peningkatan Surplus produsen pada saat jalan yang rusak dan jalan yang sudah diperbaiki adalah sebesar Rp. 13.189.000,00.

\section{Rumus perhitungan}

a. Menghitung Manfaat Proyek

Apabila suku bungga $=17.00 \%$

P tahun ke 1

$=$ Juta Rp. 13.189,00

P tahun ke 4

$=\mathrm{F} /\left((1+\mathrm{i})^{\wedge} \mathrm{n}\right)$

$=$ Juta Rp. 13.189,00 / ((1+0,17)^4)

$=$ Juta Rp. $7.038,31$

P tahun 20

$=\mathrm{F} /\left((1+\mathrm{i})^{\wedge} \mathrm{n}\right)$

= Juta Rp. 13.189,00 / ((1+0,17)^20)

$=$ Juta Rp. 570,81

b. Menghitung Biaya Proyek

$$
\begin{array}{ll}
\text { P tahun ke 1 } & =\text { Juta Rp. 67.788,48 } \\
\text { P tahun ke } 4 & =\mathrm{F} /\left((1+\mathrm{i})^{\wedge} \mathrm{n}\right) \\
& =\text { Juta Rp. } 677,88 /\left((1+0,17)^{\wedge} 3\right) \\
& =\text { Juta Rp. } 361,75 \\
\text { P tahun ke 6 } & =\mathrm{F} /\left((1+\mathrm{i})^{\wedge} \mathrm{n}\right) \\
& =\text { Juta Rp. } 3 \cdot 389,42 /\left((1+\mathrm{i})^{\wedge} 6\right) \\
& =\text { Juta Rp. } 1 \cdot 321,33 \\
\mathrm{P} \text { tahun ke 20 } & =\mathrm{F} /\left((1+\mathrm{i})^{\wedge} \mathrm{n}\right) \\
& =\text { Juta Rp. } 677,88 /\left((1+0,17)^{\wedge} 20\right) \\
& =\text { Juta Rp. } 29,34
\end{array}
$$




\section{Menghitung NPV, BCR dan IRR}

sebagaimana dalam tabel di bawah ini :

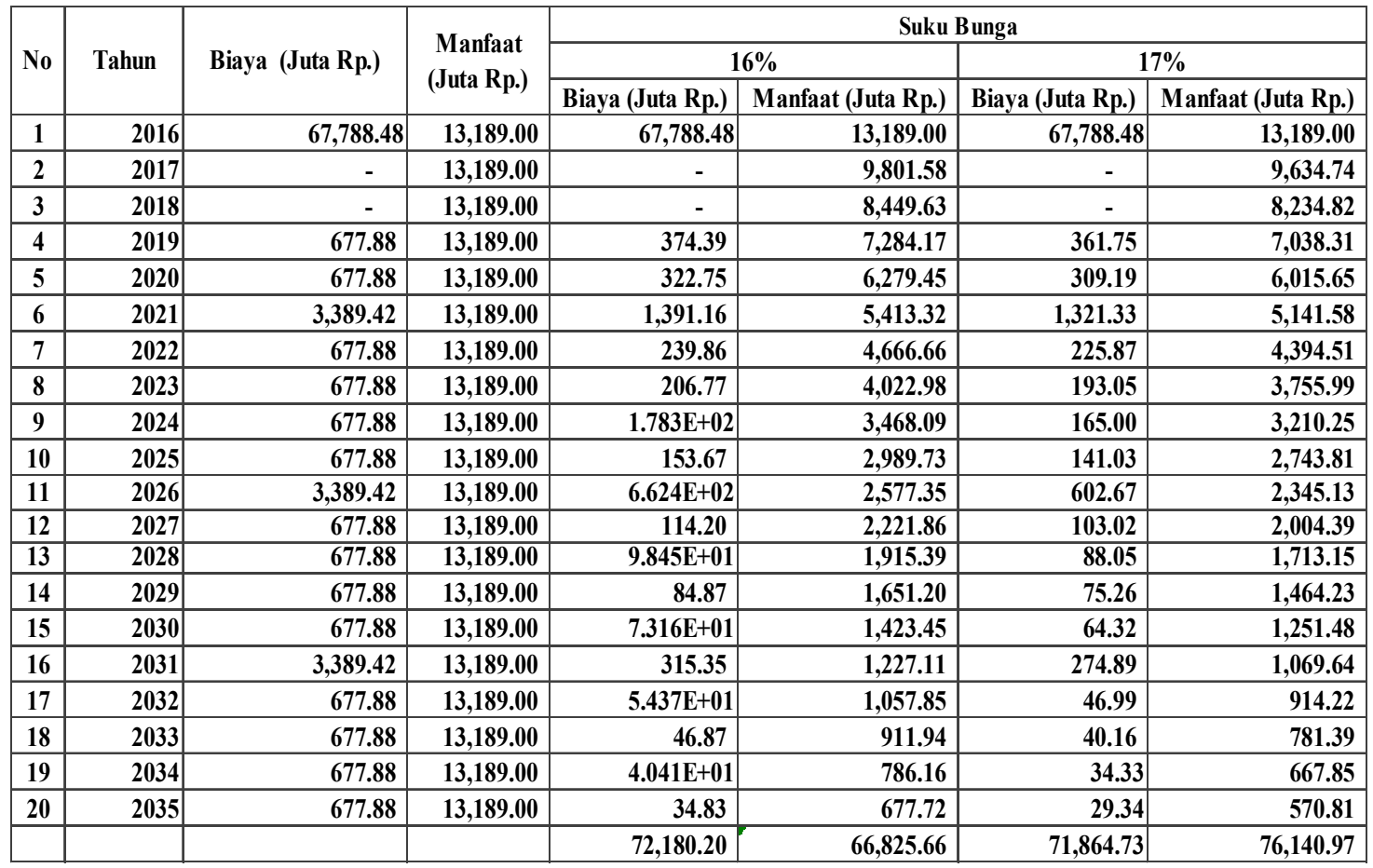

\begin{tabular}{|c|c|c|c|}
\hline \multirow{2}{*}{\multicolumn{2}{|c|}{ Parameter Kelayakan Ekonomi }} & \multicolumn{2}{|c|}{ Suku Bunga } \\
\hline & & $16 \%$ & $17 \%$ \\
\hline 1 & NPV (Net Present Value - Cost) & $(5,354.45)$ & $4,276.25$ \\
\hline 2 & BCR (Present Value Benefit / Cost) & 0.926 & 1.060 \\
\hline 3 & IRR (Internal Rate of Retur) & & $17 \%$ \\
\hline
\end{tabular}

- $\quad$ Net Present Value adalah selisih antara present Value Benefit dikurangi dengan Present Value Cost. Suatu proyek dapat diterima apabila memiliki nilai akhir yang lebih besar dari nol, Net Present Value (NPV) pada akhirnya umur rencana harus lebih besar dari pada nol. Hal tersebut menggunakan tingkat bunga untuk memperkirakan selisih antara biaya dan manfaat pada saat ini dan masa yang akan datang.

\section{NPV $=($ PVbenefit - Pvcost $)=$ Positif}

- Benefit Cost Ratio (BCR) adalah perbandingan antara Present Valur Benefit dibagi dengan Present Valur Cost. BCR dengan nilai lebih besar 1 menunjukan bahwa program pembangunan jalan akan menguntungkan, sedangkan BCR kurang dari 1 menujukan bahwa proyek tersebut tidak layak. Nilai ini dilakukan berdasarkan nilai sekarang, yaitu dengan membandingkan selisih manfaat dengan biaya yang lebih besar dari nol dan selisih manfaat dengan biaya lebih kecil dari nol. Persamaan umum dalam mengitung BCR adalah sebagai berikut:

$$
=\frac{\begin{array}{c}
\text { B/Cnett } \\
\text { Present Value Nett Benefit }
\end{array}}{\text { Capital Cost }}
$$

- Internal Rate of Return (IRR) adalah besarnya tingkat suku bunga pada saat nilai $\mathrm{NPV}=0$. Nilai IRR dari suatu 
proyek harus lebih besar dari nilai suku bunga yang berlaku atau yang ditetapkan dipakai dalam perhitungan kelyakan proyek. Nilai ini digunakan untuk memperoleh suatu tingat bunga pada kondisi NPV $=0$. Perhitungan untuk memperoleh IRR ini dilakukan dengan coba-coba. Persamaan umum untuk metode ini adalah sebagai berikut:

$$
\mathbf{N P V}=\sum_{i=\mathbf{0}}^{n}\left[(\mathbf{B i}-\mathbf{C i})+\left(\mathbf{I R R}^{-\mathbf{1}}\right)\right]
$$

\section{PENUTUP}

\section{Kesimpulan}

Kesimpulan yang didapat dari kajian kelayakan ekonomi pada ruas jalan Cianjur Sukanagara yaitu :

1. Dengan adanya perbaikan jalan Cianjur - Sukanagara peningkatan ekonomi yang didaptkan sebelum jalan diperbaiki yaitu sebesar Rp 49.735.000 dan sesudah jalan diperbaiki yaitu sebesar Rp 62.924.000 maka surplus produsen yang didapatkan sebesar $\mathrm{Rp}$ 13.189.000 .

2. Pada penelilitian analisa kelayakan ekonomi didapat NPV (Net Present Value ) sebesar 4,276.25 dengan BCR sebesar 1,060 dengan menggunakan suku bunga IRR (Internal Rate of Retur) sebesar 17\%, maka jumlah ini menunjukan jalan Cianjur - Sukanagara layak secara ekonomi.

Adanya peningkatan surplus produsen akan membuka ruang lebih terhadap daerah yang terisolir sehingga meningkatkan jalur komunikasi antar daerah yang akan berimbas pada pertumbuhan ekonomi daerah.

\section{Saran}

1. Pentingnya keterlibatan dari pihak Dinas yang terkait untuk memperhatikan, memelihara dan memperbaiki jalan agar jalan yang sudah diperbaiki tepelihara dengan baik.

2. Diperlukannya pentingkatan mutu jalan agar jalan memiliki perawatan dan perbaikan yang efisien.

\section{DAFTAR PUSTAKA}

Sekaryadi, Yudi, Tesis: Trase Jalan Alternatif Cianjur - Sindangbarang, ITB: Bandung.

Diakses tanggal 19 feb 2016 https://www.academia.edu/7423545/1 ._Pengertian_Sistem_Transportasi

Diakses tanggal 19 feb 2016 http://belajjarilmuteknik.blogspot.co.i d/2013/12/sistem-transportasi.html

Tamin, Ofyar Z, 2000, Perencanaan dan Pemodelan Transportasi, ITB, Bandung.

I GDE WIKARGA, 2014, TUGAS 1 SISTEM TRANSPORTASI MAKRO DESKRIPSI PENGERTIAN SISTEM TRANSPORTASI MAKRO DAN CONTOHNYA, PROGRAM PASCASARJANA UNIVERSITAS UDAYANA, DENPASAR

Diakses tanggal 19 feb 2016 https://taufikzk.wordpress.com/2013/ $11 / 28$ /pengertian-kota-menurut-paraahli/

Bintarto, R. Prof. Dr.. 1983.Interaksi DesaKota. Yogyakarta: Ghalia Indonesia.

Bintarto, R. Prof. Dr., 1983. Urbanisasi dan Permasalahannya. Yogyakarta: Ghalia Indonesia.

Warpani, P. Suwardjoko. (1990). Merencanakan Sistem Perangkutan. Bandung : Penerbit ITB.

Diakses tanggal 19 feb 2016 https://muhamadmuslihlatief91.wordp ress.com/2012/10/30/12-perencanaantransportasi/ 
Peraturan Pemerintah Nomor 34 tahun 2006 tentang Jalan

Undang-Undang No. 38 Tahun 2004 tentang jalan

Diakses tanggal 11 april 2016

http://repository.usu.ac.id/bitstream/123456789/33769/3/

Chapter\%20II.pdf 